\title{
Influence of the Hydrothermal Method Growth Parameters on the Zinc Oxide Nanowires Deposited on Several Substrates
}

\author{
Concepción Mejía-García, ${ }^{1}$ Elvia Díaz-Valdés, ${ }^{1}$ Marco Alberto Ayala-Torres, ${ }^{1}$ \\ Josué Romero-Ibarra, ${ }^{2}$ and Máximo López-López ${ }^{3}$ \\ ${ }^{1}$ Departamento de Física, ESFM-Instituto Politécnico Nacional, Edif. 9, UPALM, Col. San Pedro Zacatenco, 07738 México, DF, Mexico \\ ${ }^{2}$ Departamento de Ingeniería Eléctrica, CINVESTAV, Avenue IPN 2508, Col. San Pedro Zacatenco, 07360 México, DF, Mexico \\ ${ }^{3}$ Departamento de Física, CINVESTAV, Avenue IPN 2508, Col. San Pedro Zacatenco, 07360 México, DF, Mexico \\ Correspondence should be addressed to Concepción Mejía-García; concepcionmejia@gmail.com
}

Received 6 August 2014; Revised 21 October 2014; Accepted 4 November 2014; Published 18 November 2014

Academic Editor: Shadi A. Dayeh

Copyright ( 2014 Concepción Mejía-García et al. This is an open access article distributed under the Creative Commons Attribution License, which permits unrestricted use, distribution, and reproduction in any medium, provided the original work is properly cited.

\begin{abstract}
We report the synthesis of $\mathrm{ZnO}$ nanowires grown on several substrates (PET, glass, and $\mathrm{Si}$ ) using a two-step process: (a) preparation of the seed layer on the substrate by spin coating, from solutions of zinc acetate dihydrate and 1-propanol, and (b) growth of the $\mathrm{ZnO}$ nanostructures by dipping the substrate in an equimolar solution of zinc nitrate hexahydrate and hexamethylenetetramine. Subsequently, films were thermally treated with a commercial microwave oven (350 and $700 \mathrm{~W})$ for 5, 20, and $35 \mathrm{~min}$. The $\mathrm{ZnO}$ nanowires obtained were characterized structurally, morphologically, and optically using XRD, SEM, and UV-VIS transmission, respectively. XRD patterns spectra revealed the presence of $\mathrm{Zn}(\mathrm{OH})_{2}$ on the films grown on glass and Si substrates. A preferential orientation along c-axis directions for films grown on PET substrate was observed. An analysis by SEM revealed that the growth of the $\mathrm{ZnO}$ nanowires on PET and glass is better than the growth on $\mathrm{Si}$ when the same growth parameters are used. On glass substrates, $\mathrm{ZnO}$ nanowires less than $50 \mathrm{~nm}$ in diameter and between $200 \mathrm{~nm}$ and $1200 \mathrm{~nm}$ in length were obtained. The ZnO nanowires band gap energy for the films grown on PET and glass was obtained from optical transmission spectra.
\end{abstract}

\section{Introduction}

Zinc oxide $(\mathrm{ZnO})$ is an interesting material due to its excellent optical, chemical, electrical, and piezoelectric properties [14]. $\mathrm{ZnO}$ is an n-type oxide semiconductor material and has been investigated since it has very stable thermal characteristics, with a direct wide band gap of $3.37 \mathrm{eV}$, a large exciton binding energy of $60 \mathrm{meV}$, and transparent conductivity. $\mathrm{ZnO}$ nanowires are one dimensional (1D) structures with remarkable physical properties. Comparing with carbon nanotubes, $\mathrm{ZnO}$ nanowires have a good mechanical strength and thermal and chemical stability; thus they are potential substitute of carbon nanotubes. $\mathrm{ZnO}$ nanowires are widely applied in the field of optoelectronic and nanomechanics, such as in ultraviolet light-emitting diodes, varistors, surface acoustic wave (SAW) components, transparent electrodes for solar cell window, gas sensors, and photocatalysts $[5,6]$.
Physical, chemical, and electrochemical methods have been carried out for achieving $\mathrm{ZnO}$ nanowires; some of these are metal-organic vapor-phase epitaxy, chemical vapor deposition, and hydrothermal deposition $[7,8]$. Hydrothermal method has attracted much attention in the field of $\mathrm{ZnO}$ nanostructures growth because of the simplicity of the required equipment in the growth process and the possibility of low temperature implementation [9]. In that work, $\mathrm{ZnO}$ well aligned single crystalline hexagonal nanowires of 100 $200 \mathrm{~nm}$ wide at $95^{\circ} \mathrm{C}$ were obtained. A disadvantage of this method is the time required for the synthesis of nanowires spanning from several hours to days [10]. Several methods have been suggested in order to increase the growth rate of hydrothermally grown $\mathrm{ZnO}$ nanowires. A microwave assisted hydrothermal method with the aim of rapid heating of the solution and so reducing the time needed for reaching the crystallization temperature in the growth environment has been carried out successfully [11]. 
TABLE 1: Growth parameters, XRD results, nanowire diameter, and band gap energy for samples of ZnO nanowires grown on PET, glass, and Si.

\begin{tabular}{|c|c|c|c|c|c|}
\hline Sample & Power (W) & Heating time (min) & Highest XRD reflections & Nanowire diameter $(\mathrm{nm})$ & Energy $(\mathrm{eV})$ \\
\hline PZO1 & 700 & 5 & $(002)$ & $180-200$ & 3.28 \\
\hline $\mathrm{PZO} 2$ & 700 & 20 & $(002)$ & 90 & 3.28 \\
\hline PZO3 & 700 & 35 & $(100)$ & $80-100$ & 3.28 \\
\hline $\mathrm{PZO} 4$ & 350 & 5 & (100), (002), (101) & 140 & 3.29 \\
\hline PZO5 & 350 & 20 & $(100)$ & 90 & - \\
\hline PZO6 & 350 & 35 & $(100)$ & 180 & 3.28 \\
\hline GZO1 & 700 & 5 & $(002)$ & 200 & 3.27 \\
\hline GZO2 & 700 & 20 & (100), (002) & 200 & 3.22 \\
\hline GZO3 & 700 & 35 & (100), (002), (101) & $100-200$ & 3.33 \\
\hline GZO4 & 350 & 5 & $(100)$ & $<25$ & 3.33 \\
\hline GZO5 & 350 & 20 & (100), (101) & $200-600$ & - \\
\hline GZO6 & 350 & 35 & Not preferred orientation & $50-100$ & 3.22 \\
\hline SZO1 & 700 & 5 & $(002)$ & $80-200$ & \\
\hline $\mathrm{SZO} 2$ & 700 & 20 & (100), (002), (101) & $70-200$ & \\
\hline $\mathrm{SZO} 3$ & 700 & 35 & $(101)$ & $70-200$ & \\
\hline $\mathrm{SZO} 4$ & 350 & 5 & $(100)$ & $200-400$ & \\
\hline SZO5 & 350 & 20 & - & - & \\
\hline SZO6 & 350 & 35 & $(100)$ & $200-400$ & \\
\hline
\end{tabular}

In this work, $\mathrm{ZnO}$ nanowires are grown on several substrates (PET, glass, and $\mathrm{Si}$ ) by hydrothermal method using the same growth parameters in order to determine the influence of the substrate in the vertical alignment of the $\mathrm{ZnO}$ nanowires. To obtain $\mathrm{ZnO}$ nanowires efficiently a commercial microwave oven for rapid heating of the material was used. With this procedure the processing time for growing $\mathrm{ZnO}$ nanowires can be reduced up to $1 \mathrm{~min}$ [12].

The $\mathrm{ZnO}$ nanowires were characterized structurally, morphologically, and optically by X-ray diffraction, scanning electron microscopy (SEM), and UV-VIS transmission measurements at room temperature.

\section{Materials and Methods}

$\mathrm{ZnO}$ nanowires were grown hydrothermally on several substrates such as polyethylene terephthalate (PET), glass, and ptype Si (100) based on the method developed by Unalan et al. [11]. This method consists in two-step process: (a) preparation of the $\mathrm{ZnO}$ seed layer and (b) growth of the nanostructures. First step: solutions of zinc acetate dihydrate and 1-propanol of $10 \mathrm{mM}$ concentration were spin coated on the substrate at $2000 \mathrm{rpm}$ for $54 \mathrm{~s}$ at room temperature using a syringe pump; then the substrate was annealed at $100^{\circ} \mathrm{C}$ for $60 \mathrm{~s}$.

A $\mathrm{ZnO}$ seed layer was obtained after three of such cycles. Second step: vertical $\mathrm{ZnO}$ nanowires were grown by dipping the substrate in a $25 \mathrm{mM}$ equimolar solution of zinc nitrate hexahydrate $\left(\mathrm{Zn}\left(\mathrm{NO}_{3}\right)_{2} \cdot 6 \mathrm{H}_{2} \mathrm{O}\right)$ and hexamethylenetetramine (HMTA) solution in deionized water. Subsequently, films were thermally treated with a commercial microwave oven at different power settings (350 and $700 \mathrm{~W}$ ) for 5, 20, and $35 \mathrm{~min}$. Finally, the substrates were taken out from the growth solution, rinsed with deionized water, and dried under nitrogen flow. Prior to spin coating, the substrates were cleaned by sonication in acetone and isopropanol for $12 \mathrm{~min}$ and dried in a nitrogen flow.

The morphological, structural, and optical properties of the $\mathrm{ZnO}$ nanowires were studied by scanning electron microscopy (SEM), X-ray diffraction (XRD), and optical transmission (OT), respectively. SEM system was operated at $5 \mathrm{kV}$ in order to obtain the $\mathrm{ZnO}$ nanowire images with a secondary electron detector in a Zeiss MOD Auriga 3916 microscopy. The X-ray diffraction patterns were measured in Grazing-incidence small-angle X-ray scattering (GISAXS) with Xpert PRO Diffractometer from PANalytical using $\mathrm{Cu}$ radiation $\left(\mathrm{K}_{\alpha}=1.54 \AA\right)$. Optical transmission measurements were obtained with a Spectrometer UV/VIS Lambda 35 Perkin-Elmer in the region of $300 \mathrm{~nm}$ to $1100 \mathrm{~nm}$. Table 1 shows the main growth parameters (power of microwave oven and heating time) used during the growth of $\mathrm{ZnO}$ nanowires on different substrates. The first letter of the sample names referred to the substrate used; P for PET, G for glass, and $\mathrm{S}$ for $\mathrm{Si}$.

\section{Results and Discussion}

3.1. XRD Patterns. Figures 1,2 , and 3 show Bragg-Brentano $\theta$-20XRD scans for samples PZO1 to PZO6, GZO1 to GZO6, and SZO1 to SZO6, grown at different conditions of thermal treatment on PET substrates, glass substrates, and Si substrates, respectively. The thermal treatment was performed at $350 \mathrm{~W}$ and $700 \mathrm{~W}$ for different times: $5 \mathrm{~min}, 20 \mathrm{~min}$, and $35 \mathrm{~min}$.

In the XRD scans of Figure 1 we identify the crystalline phase of zinc oxide (Zincite); the reflections with highest intensity are summarized in Table 1 . When the furnace power 


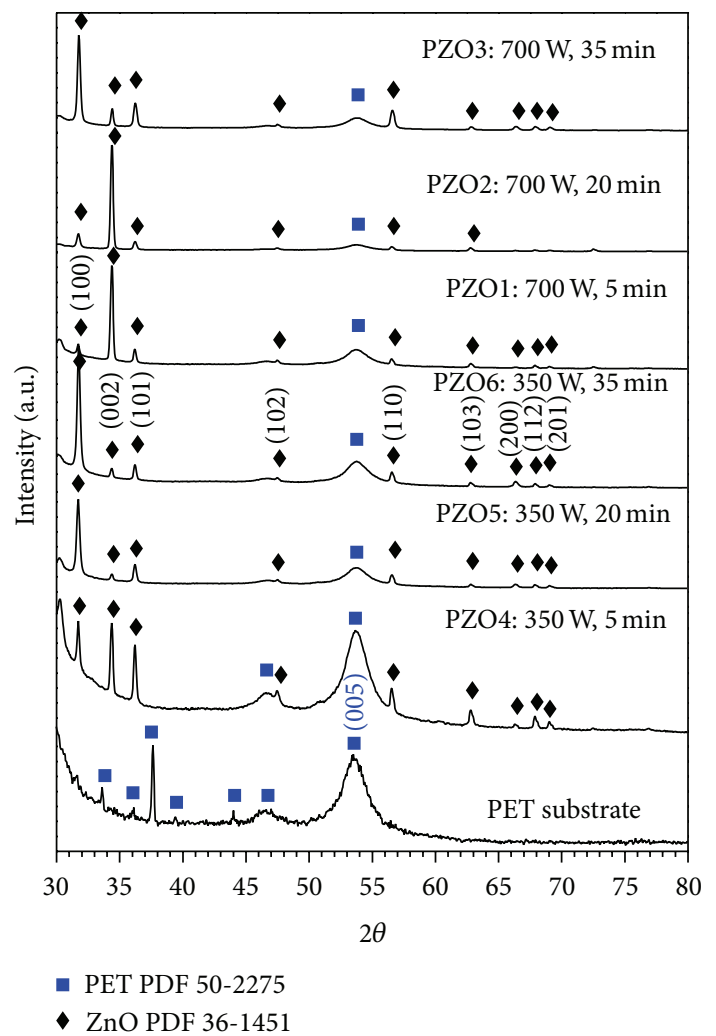

FIgURE 1: XRD profiles for $2 \theta$ in the range from $30^{\circ}$ to $80^{\circ}$ for all samples of $\mathrm{ZnO}$ nanowires on PET substrate grown at several conditions.

was $350 \mathrm{~W}$ and the treatment time was $20 \mathrm{~min}$ and $35 \mathrm{~min}$, the intensity of the reflection (100) of $\mathrm{ZnO}$ has the highest intensity, with a preferential growing in the a-axis direction. When applying a heating time of $5 \mathrm{~min}$, the intensity of the reflections of $\mathrm{ZnO}$, in the directions (100), (002), and (101), was the highest and there was no preferential orientation. When the furnace power was increased to $700 \mathrm{~W}$ and the heating time was $5 \mathrm{~min}$ and $20 \mathrm{~min}$, the highest intensity was obtained for the reflection (002) indicating the preferential growing in the c-axis direction in accordance with the results of Unalan et al. [11] and Vayssieres [9]. On the other hand, applying $35 \mathrm{~min}$ of heating time leads to the highest intensity in the reflection (100) with a preferential growing in the $a$ axis direction. Furthermore, the thickest film was obtained when the furnace power was $700 \mathrm{~W}$ and $20 \mathrm{~min}$ of heating time. The signal of the PET substrate can be observed even to high power and large heating time in the furnace. However, the thickness of the film is not thick enough to block the substrate signal. In the thermal treatment conditions studied, the growth of $\mathrm{ZnO}$ nanowires is performed preferentially in the directions (100) and (002).

The crystalline phases obtained for the growth on glass substrates (Figure 2) are $\mathrm{ZnO}$ and $\mathrm{Zn}(\mathrm{OH})_{2}$. Most of the crystalline phase reflections of $\mathrm{Zn}(\mathrm{OH})_{2}$ are overlapped with the peaks associated to the $\mathrm{ZnO}$ nanowires. When the furnace power was $350 \mathrm{~W}$ and the treatment time was $5 \mathrm{~min}$ and $20 \mathrm{~min}$, the intensity of the reflections of $\mathrm{ZnO}$ in the direction (100) has the highest intensity, with a preferential growing in

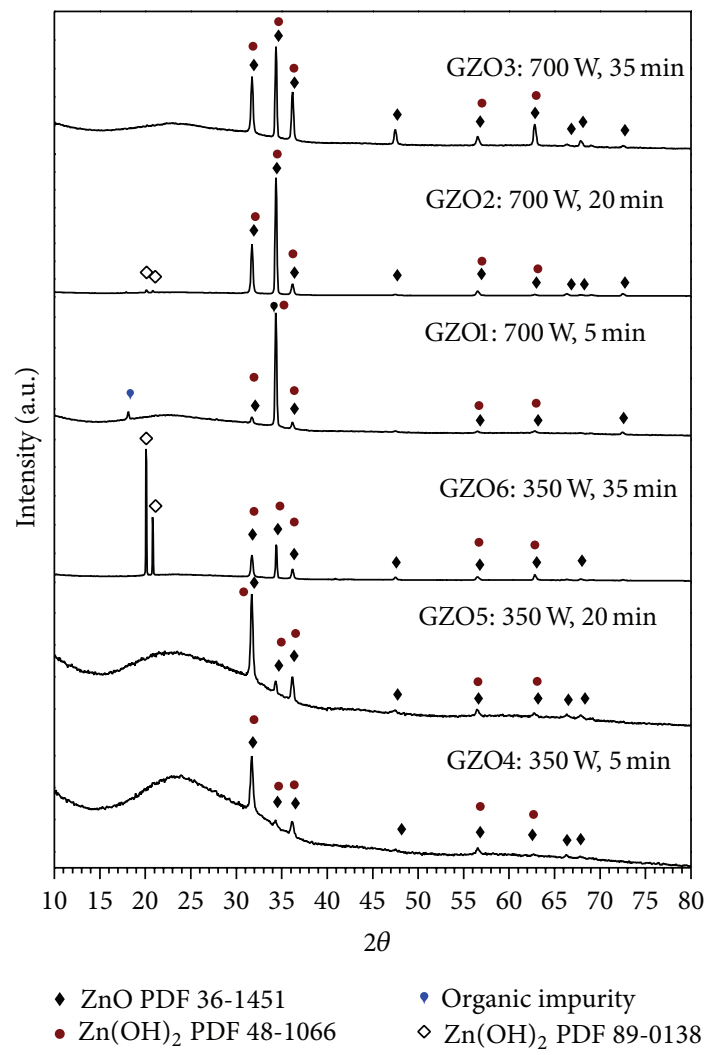

Figure 2: XRD profiles for $2 \theta$ in the range from $10^{\circ}$ to $80^{\circ}$ for all samples of $\mathrm{ZnO}$ nanowires on glass substrate grown at several conditions.

the a-axis direction. When the furnace power was increased to $700 \mathrm{~W}$ and the heating time was $5 \mathrm{~min}$ and $20 \mathrm{~min}$, as in results obtained with PET, the highest intensity was obtained for the reflection (002) indicating the preferential orientation in the c-axis direction. When applying a heating time of $35 \mathrm{~min}$, in both furnace powers, $350 \mathrm{~W}$ and $700 \mathrm{~W}$, the intensity of the reflections of $\mathrm{ZnO}$, in the directions (100), (002), and (101), was the highest and there was no preferential orientation. We can observe that the intensity of the peaks increases for a larger heating time, in particular the peaks at $31^{\circ}(100)$ and $36^{\circ}$ (101) for high power setting (700 W) but not at low power $(350 \mathrm{~W})$. There is a trace phase of an organic impurity in sample GZO1 and a $\mathrm{Zn}(\mathrm{OH})_{2}$ phase (PDF 890138 ) around $20^{\circ}$ in samples GZO2 and GZO6. It can be observed that the $\mathrm{Zn}(\mathrm{OH})_{2}$ phase (PDF 89-0138) disappears when the power increases to $700 \mathrm{~W}$ and the intensity of the peaks corresponding to the $\mathrm{ZnO}$ nanowires increases.

As for the deposition on $\mathrm{Si}$ substrates as observed in Figure 3, when the furnace power was $350 \mathrm{~W}$ and the heating time was $35 \mathrm{~min}$, we obtained a better coverage of the Si substrate since the intensity of its highest reflection decreases. We observed also this decrease when the furnace power was $700 \mathrm{~W}$ and for a heating time of 5,20 , and $35 \mathrm{~min}$. The $\mathrm{ZnO}$ reflection (100) increases at low power and small time of treatment in the furnace $(350 \mathrm{~W}, 5 \mathrm{~min})$. For a high power $(700 \mathrm{~W})$, the reflections increase as a function of the heating time. This can be observed comparing the intensities of 


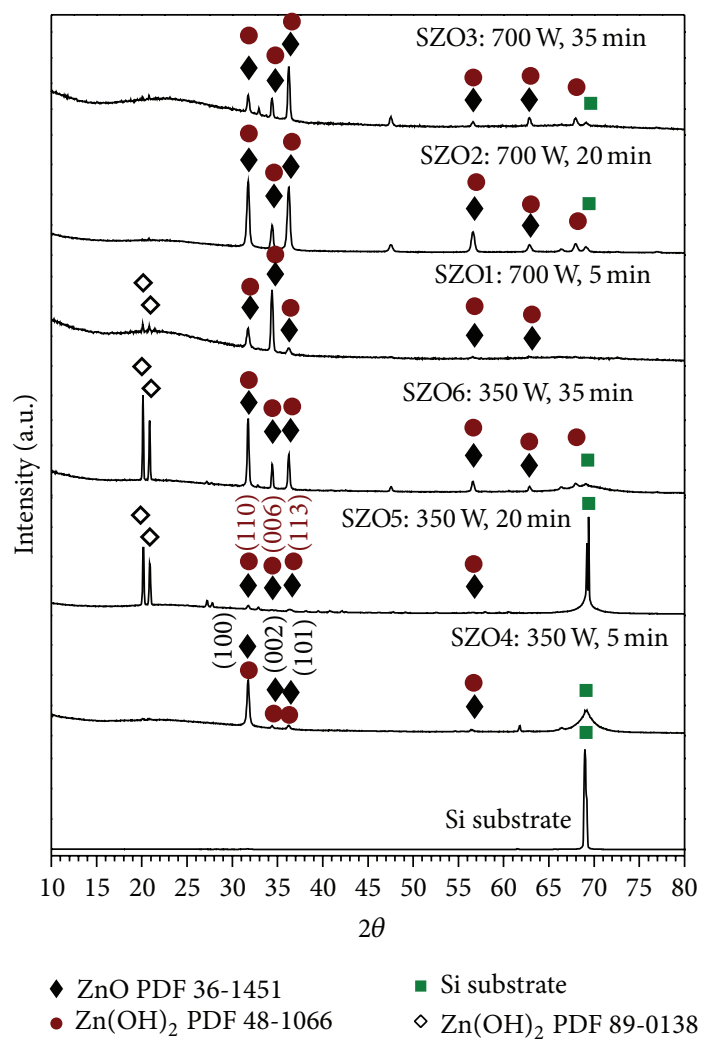

FIgURE 3: XRD profiles for $2 \theta$ in the range from $10^{\circ}$ to $80^{\circ}$ for all samples of $\mathrm{ZnO}$ nanowires on $\mathrm{Si}$ substrate grown at several conditions.

the $\mathrm{Zn}(\mathrm{OH})_{2}$ phase (PDF 89-0138). The reflection (002) increases for a heating time of $5 \mathrm{~min}$ indicating the preferential growing in the $c$-axis direction. The reflections (100) and (101) increase for a heating time of $20 \mathrm{~min}$. The reflections (101) increase for a heating time of $35 \mathrm{~min}$. For the case of $\mathrm{Zn}(\mathrm{OH})_{2}$ phase (PDF 89-0138), which appears at lower power $(350 \mathrm{~W})$ and for a heating time of $20 \mathrm{~min}$, its relative intensity increases when the heating time increases to $35 \mathrm{~min}$ and decreases when the power furnace increases at $700 \mathrm{~W}$ and the heating time is $5 \mathrm{~min}$. This reflection decreases to a trace level for higher heating times.

3.2. Scanning Electron Microscopy. SEM images of the $\mathrm{ZnO}$ nanowires arrays grown at $700 \mathrm{~W}$ and $350 \mathrm{~W}$ for (a) 5, (b) 20 , and (c) 35 min on PET, glass, and Si substrates are shown in Figures 4 to 9 , respectively.

The growth of the nanowires aligned vertically on the PET substrates, for heating time of $5 \mathrm{~min}$ and $20 \mathrm{~min}(700 \mathrm{~W}$ of furnace power), is clearly observed in Figures 4(a) and 4(b), besides the hexagonal cross section of the wires (wires diameters are summarized in Table 1). These are in agreement with the XRD results where the preferential growing of the (002) planes is observed. For a heating time of $5 \mathrm{~min}$, the diameters vary between 180 and $200 \mathrm{~nm}$ approximately; for $20 \mathrm{~min}$, the average diameter is $90 \mathrm{~nm}$ approximately. While in Figure 4(c), heating time of $35 \mathrm{~min}$, the nanowires grew in random directions and the diameter, between 80 and
$100 \mathrm{~nm}$ approximately, decreases in needle tip form; on the other hand, by XRD it is observed that the planes (100) grew preferentially. In these conditions of heating time and furnace power, increasing the time, the diameter of the nanowires decreases but it is observed their length increases. As for example, at 5 and $20 \mathrm{~min}$ the length is $200 \mathrm{~nm}$ approximately, but at $35 \mathrm{~min}$ the length increases to $300-400 \mathrm{~nm}$. As we can see, over PET, the nanowires increased to twice the length, when the furnace power is set at $700 \mathrm{~W}$. This is in agreement with our previous work [12].

We observed growth of the nanowires (Figure 5(a)) for a heating time of $5 \mathrm{~min}(350 \mathrm{~W}$ of furnace power) and that according to $\mathrm{XRD}$ results, the reflections of the planes (100), (002), and (101) were of the highest intensity. In these conditions a preferential growth was not observed and the nanowires diameter was $140 \mathrm{~nm}$ approximately. In Figure 5(b) the nanowires grew parallel to the substrate but randomly orientated for a heating time of $20 \mathrm{~min}(350 \mathrm{~W})$. By XRD a preferential growth of the planes (100) is observed. The nanowires diameter was of $90 \mathrm{~nm}$ approximately. Besides, the growth at $20 \mathrm{~min}$ shows also $\mathrm{ZnO}$ structures like bars with diameters larger than the nanowires that possibly are concerned to precipitates from the source solution for the nanowires growing. In Figure 5(c) the film shows the growth of nanowires but also particles of seed-like $\mathrm{ZnO}$, for a heating time of $35 \mathrm{~min}(350 \mathrm{~W})$. XRD results indicate that the (100) planes grew preferentially. The nanowires diameter was of $180 \mathrm{~nm}$ approximately. We observed that at $350 \mathrm{~W}$ and heating time of 5 and $35 \mathrm{~min}$, the length is of $330 \mathrm{~nm}$ in average, but with $20 \mathrm{~min}$ of heating time the diameter is $90 \mathrm{~nm}$ and the length of the nanowires is $660-1000 \mathrm{~nm}$. However, $\mathrm{ZnO}$ structures like bars of $400 \mathrm{~nm}$ in diameter and $3500 \mathrm{~nm}$ in length, approximately, were obtained.

The $\mathrm{ZnO}$ nanowires grow vertically aligned on glass substrates at $700 \mathrm{~W}$ for a heating time of $5 \mathrm{~min}$ (Figure 6(a)). The hexagonal cross section of the wires can be clearly observed in the SEM images. This is in agreement with the XRD results where the preferential growth of the (002) planes is observed. The diameters of the $\mathrm{ZnO}$ nanowires are around $200 \mathrm{~nm}$. For a longer heating time of $20 \mathrm{~min}$ the XRD reflections of the planes (100) and (002) were of the highest intensity and the nanowires diameter was $200 \mathrm{~nm}$ (Figure 6(b)). On the other hand, it can be observed that, for a heating time of $35 \mathrm{~min}$ (Figure 6(c)), the $\mathrm{ZnO}$ nanowires do not grow vertically but parallel to the substrate and with a length from $200 \mathrm{~nm}$ to $1200 \mathrm{~nm}$ and diameters between 100 and $200 \mathrm{~nm}$. This is in agreement with XRD results where in these conditions a preferential growth of the nanowires was not observed. We observed that when the heating increases to $35 \mathrm{~min}$ at $700 \mathrm{~W}$, the nanowire length increases significantly.

On the other hand, $\mathrm{ZnO}$ nanowires grown at $350 \mathrm{~W}$ on glass substrates for a heating time of 5 min showed a vertical alignment according to XRD results, and the reflection of the plane (100) was of the highest intensity. The $\mathrm{ZnO}$ nanowires were grown with diameter smaller than $25 \mathrm{~nm}$ (Figure 7 (a)). For the sample processed at $350 \mathrm{~W}$ for $20 \mathrm{~min}$, it can be observed that the $\mathrm{ZnO}$ nanowires were grown with diameters between 200 and $600 \mathrm{~nm}$ with no preferential growth. From the XRD results the reflections of planes (100) and (101) 


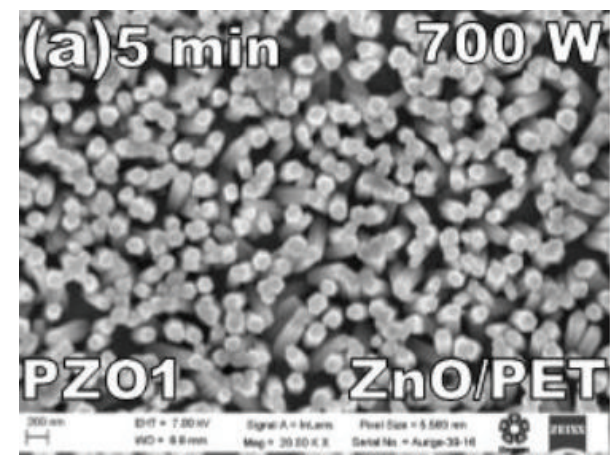

(a)

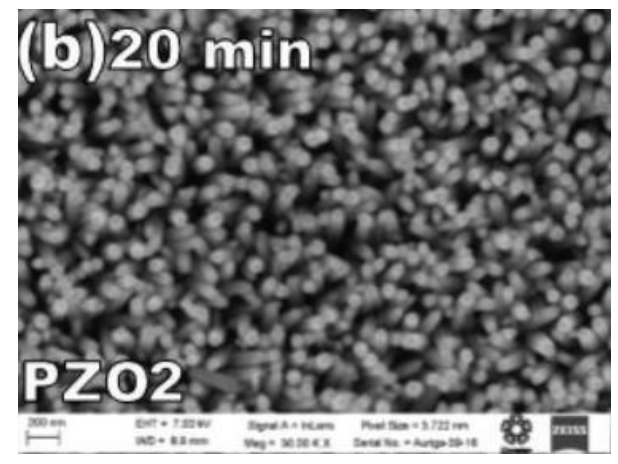

(b)

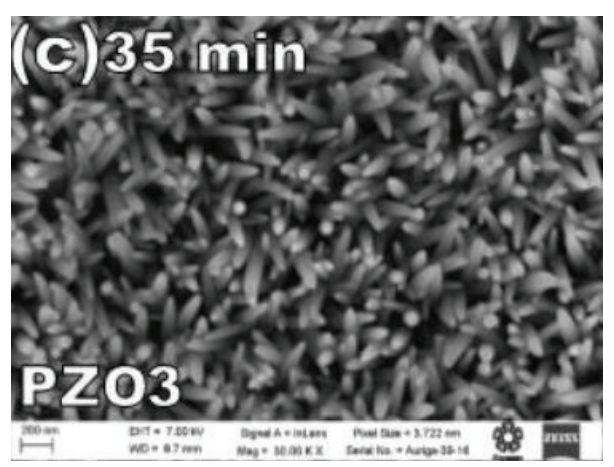

(c)

Figure 4: Scanning electron microscopy images of the $\mathrm{ZnO}$ nanowires grown on PET substrate at $700 \mathrm{~W}$ and with a heating time of (a) 5 min, (b) $20 \mathrm{~min}$, and (c) $35 \mathrm{~min}$. Scale bar of $200 \mathrm{~nm}$.

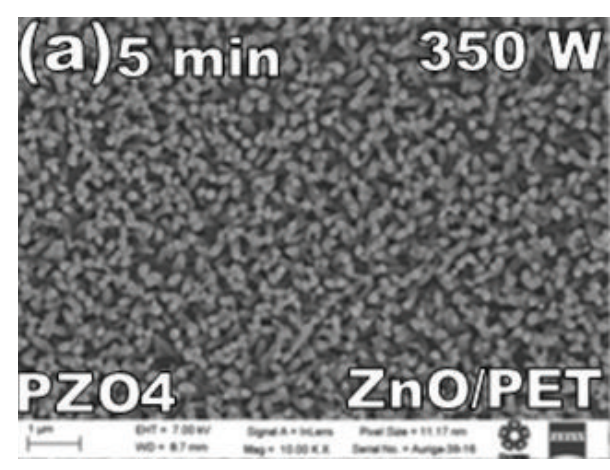

(a)

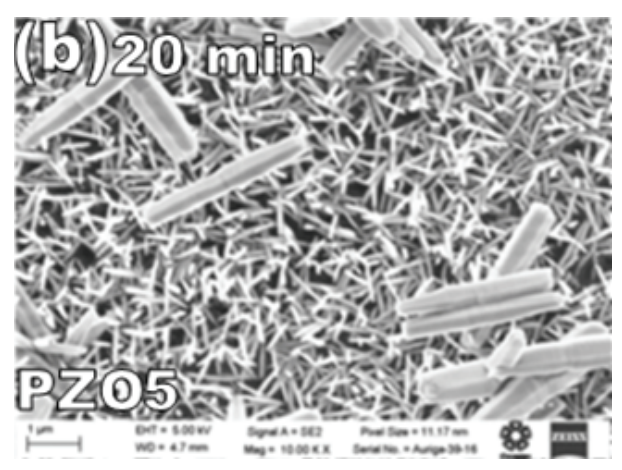

(b)

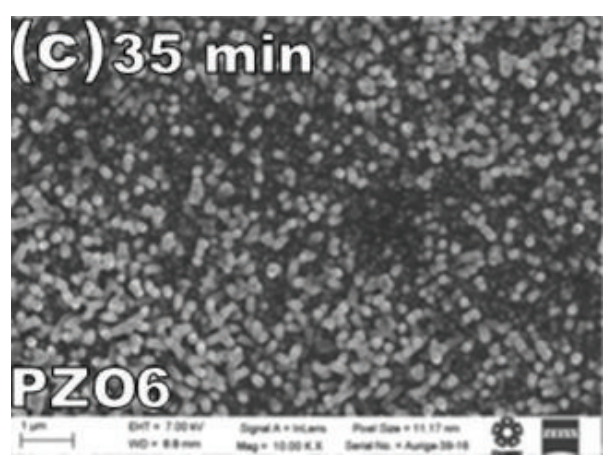

(c)

FIGURE 5: Scanning electron microscopy images of the $\mathrm{ZnO}$ nanowires grown on PET substrate at $350 \mathrm{~W}$ and with a heating time of (a) 5 min, (b) $20 \mathrm{~min}$, and (c) $35 \mathrm{~min}$. Scale bar of $1 \mu \mathrm{m}$. 


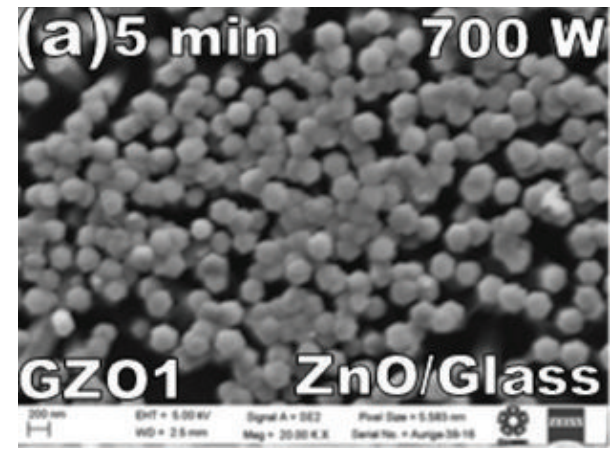

(a)

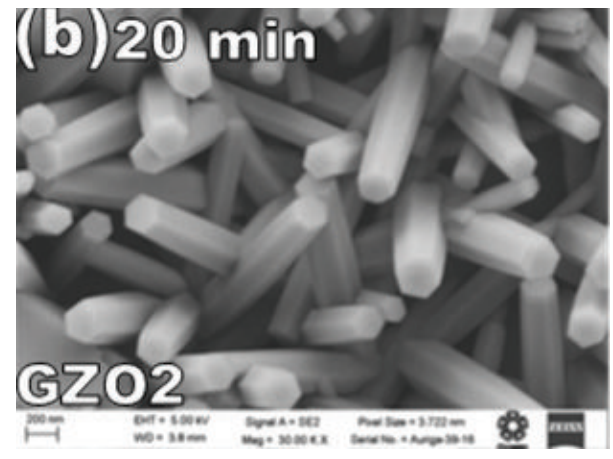

(b)

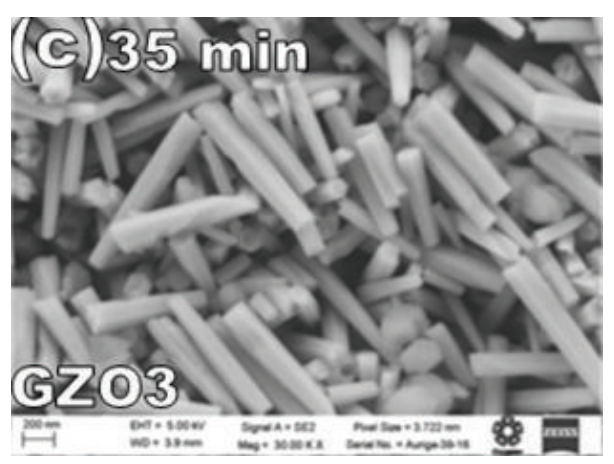

(c)

FIGURE 6: Scanning electron microscopy images of the $\mathrm{ZnO}$ nanowires grown on glass substrate at $700 \mathrm{~W}$ and with a heating time of (a) $5 \mathrm{~min}$, (b) $20 \mathrm{~min}$, and (c) $35 \mathrm{~min}$. Scale bar of $200 \mathrm{~nm}$.

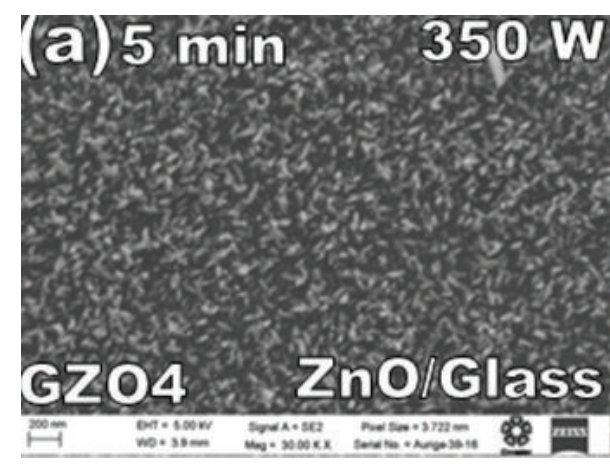

(a)

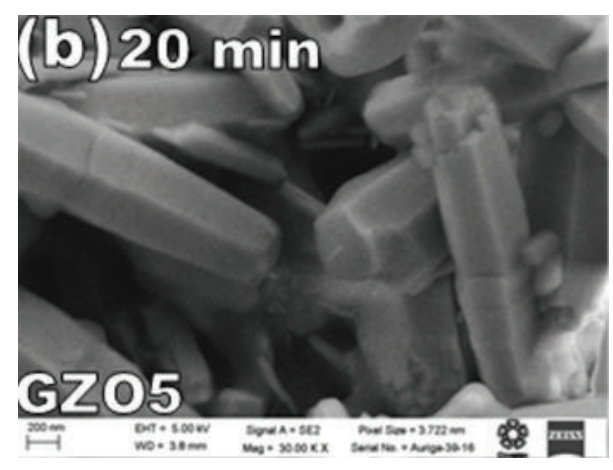

(b)

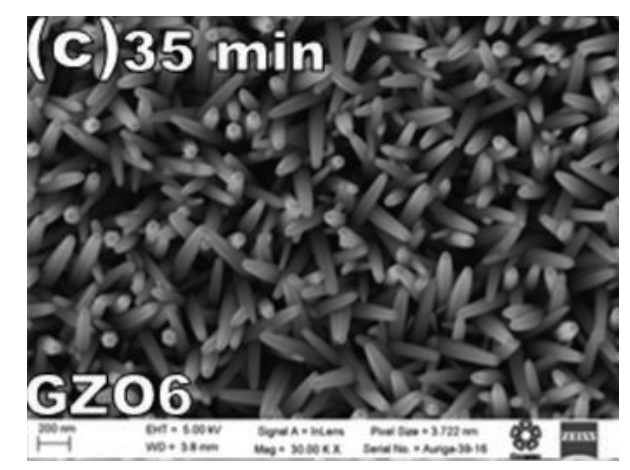

(c)

FIGURE 7: Scanning electron microscopy images of the $\mathrm{ZnO}$ nanowires grown on glass substrate at $350 \mathrm{~W}$ and with a heating time of (a) 5 min, (b) $20 \mathrm{~min}$, and (c) $35 \mathrm{~min}$. Scale bar of $200 \mathrm{~nm}$. 


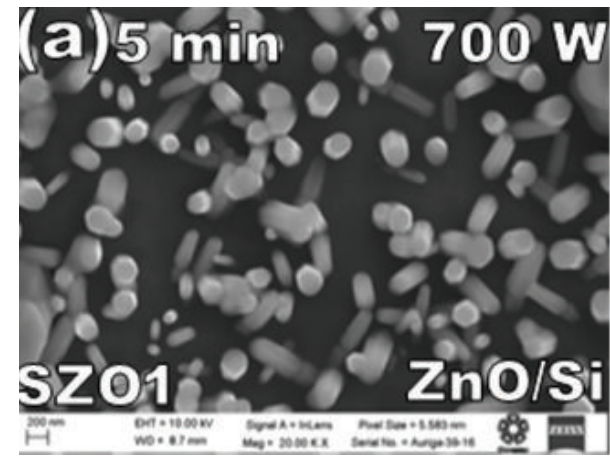

(a)

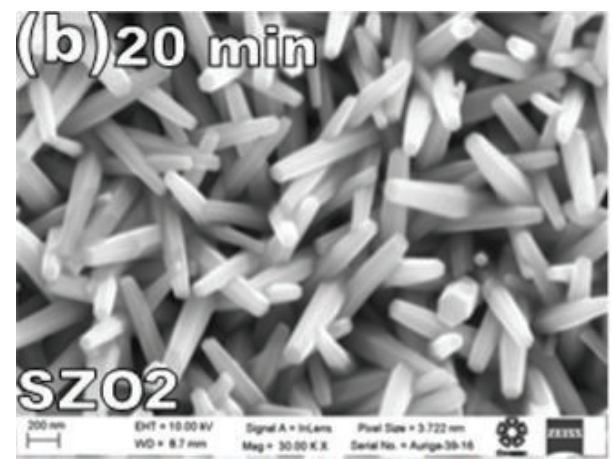

(b)

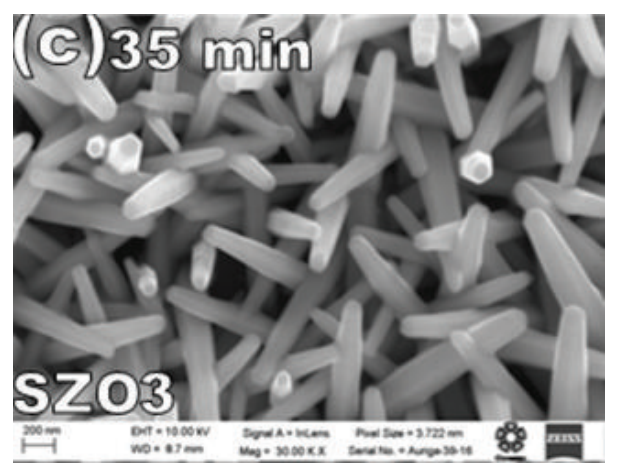

(c)

FIGURE 8: Scanning electron microscopy images of the $\mathrm{ZnO}$ nanowires grown on Si substrate at $700 \mathrm{~W}$ and with a heating time of (a) 5 min, (b) $20 \mathrm{~min}$, and (c) $35 \mathrm{~min}$. Scale bar of $200 \mathrm{~nm}$.

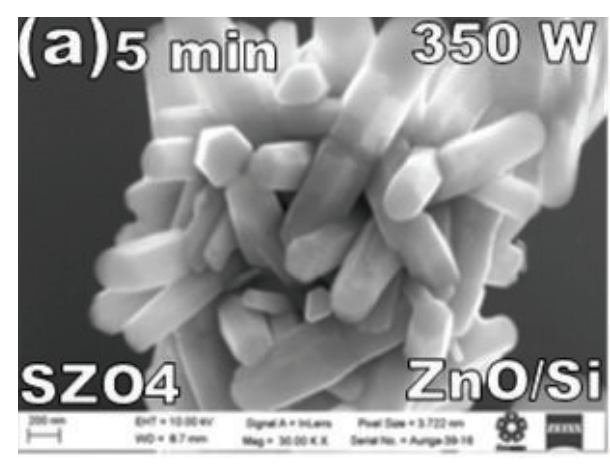

(a)

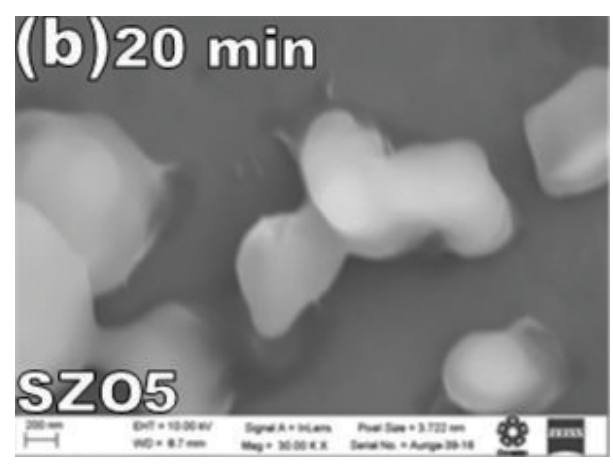

(b)

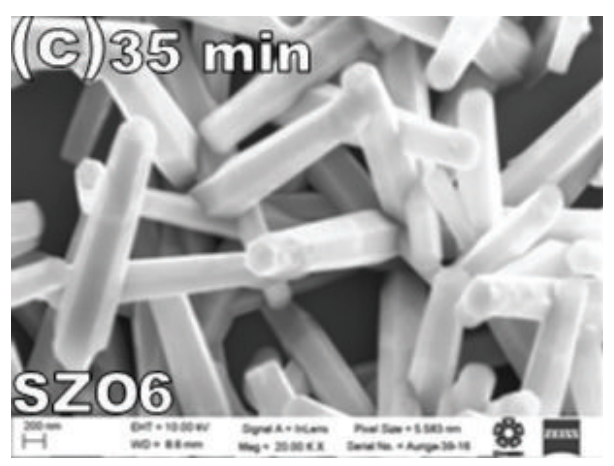

(c)

FIGURE 9: Scanning electron microscopy images of the $\mathrm{ZnO}$ nanowires grown on Si substrate at $350 \mathrm{~W}$ and with a heating time of (a) $5 \mathrm{~min}$, (b) $20 \mathrm{~min}$, and (c) $35 \mathrm{~min}$. Scale bar of $200 \mathrm{~nm}$. 
were of the highest intensity (Figure 7(b)). In both samples, the XRD signal of the glass substrate was strong obtaining thin films. However, at $350 \mathrm{~W}$ for a heating time of $35 \mathrm{~min}$ (Figure $7(\mathrm{c})$ ), the nanowires grew in random directions and the diameter, between 50 and $100 \mathrm{~nm}$ approximately, decreases in needle tip form. This is in agreement with XRD results where a preferential growth was not observed. We observed that with heating time of 5 and $35 \mathrm{~min}$, the length is 100 and $400 \mathrm{~nm}$, respectively. But with $20 \mathrm{~min}$ of heating, the length increased to $2000 \mathrm{~nm}$ approximately.

For the deposition on $\mathrm{Si}$ substrates (Figure 8), $\mathrm{ZnO}$ nanowires grew vertically aligned for a heating time of $5 \mathrm{~min}$ at $700 \mathrm{~W}$, but with a low density, and according to XRD results, the reflection of the plane (002) was the highest in intensity. The diameter of these nanowires was between $80-$ $200 \mathrm{~nm}$ and $450 \mathrm{~nm}$ of length. By increasing heating time to $20 \mathrm{~min}$ the nanowires grew randomly orientated, as observed in Figure $8(\mathrm{~b})$. This is in agreement with the XRD results where the reflections of planes (100), (002), and (101) were of the highest intensity. The diameter of the nanowires was between 70 and $200 \mathrm{~nm}$ and decreases to the tip, while the length for this heating time increased to $500-900 \mathrm{~nm}$. The same diameters were obtained for sample processed during $35 \mathrm{~min}$, but the nanowires length increased to $600-1200 \mathrm{~nm}$; see Figure 8(c). In this sample, the reflection (101) has the highest intensity.

By decreasing the furnace power to $350 \mathrm{~W}$ (Figure 9) we observed that, for short heating time $(5 \mathrm{~min})$, the $\mathrm{ZnO}$ nanowires are not aligned and grow as clusters where by XRD the reflection of highest intensity was the (100). The nanowires diameters were between $200 \mathrm{~nm}$ and $400 \mathrm{~nm}$. But for 35 min (Figure 9(c)) the nanowires grow randomly although by XRD the highest intensity is for reflection (100). Their diameters were the same as those obtained for 5 min of heating time.

At $350 \mathrm{~W}$ and $700 \mathrm{~W}$, we observed that the length of the nanowires increased with increasing heating time.

From SEM results we observe that for samples grown on PET substrates at $350 \mathrm{~W}$, the nanowires diameter increases when the heating time increases from 5 to $35 \mathrm{~min}$ according to the growth mechanism. Increasing the furnace power at $700 \mathrm{~W}$, the nanowires diameter decreases in needle tip form, but their length is increased. This is in agreement with Unalan et al. [11]. For samples grown on glass substrates at $350 \mathrm{~W}$, a relationship between the heating time and the nanowires diameter was not observed. At $700 \mathrm{~W}$ the nanowires diameter remains almost constant in $200 \mathrm{~nm}$, independently of the heating time conditions. For samples grown on Si substrates at $350 \mathrm{~W}$ and $700 \mathrm{~W}$, the interval of the nanowires diameter remains constant from $200 \mathrm{~nm}$ to $400 \mathrm{~nm}$ and from $70 \mathrm{~nm}$ to $200 \mathrm{~nm}$, respectively. This shows that the nanowires diameter grown on $\mathrm{Si}$ is independent of the heating time. Both on PET and on glass it is observed that the growth of nanowires with $35 \mathrm{~min}$ of heating decreases the diameter of the same but increases its length. Besides, it can be observed that the samples grown on PET substrates show a better alignment of the $\mathrm{ZnO}$ nanowires compared to those grown on glass or $\mathrm{Si}$ substrates.

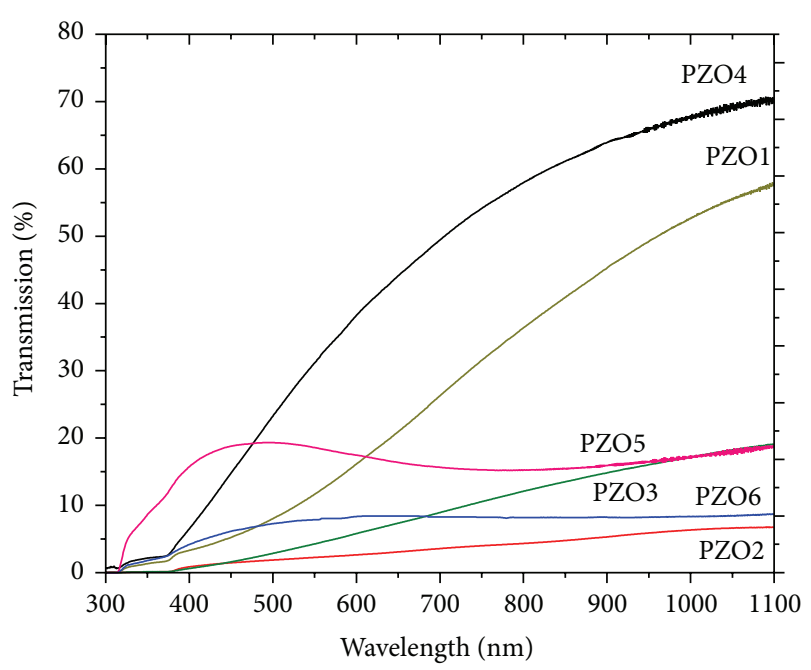

FIGURE 10: Optical transmission spectra of $\mathrm{ZnO}$ nanowires grown on PET substrate.

It was showed that, in PET, glass, and $\mathrm{Si}$ substrates, the crystal orientation changes with furnace power condition and the heating time. At $700 \mathrm{~W}$ and $5 \mathrm{~min}$, the $\mathrm{ZnO}$ nanowires exhibit a preferential alignment along $c$-axis direction. Namely, the formation of highly oriented $\mathrm{ZnO}$ nanowires requires high energy and low heating times. While at smaller furnace power as $350 \mathrm{~W}$, the strongest reflection was the (100) compared to (002) and (101), showing more isotropic and randomly oriented samples. In particular for glass substrate this behavior was observed increasing the heating time.

In a substrate area of $8 \mathrm{~mm} \times 8 \mathrm{~mm}$, approximately, we observed uniformity of deposition on glass and PET substrates. However, $\mathrm{ZnO}$ nanowires on $\mathrm{Si}$ were grown as islands dispersed over that area.

3.3. Optical Transmission. The optical transmission spectra in the range of $300 \mathrm{~nm}$ and $1100 \mathrm{~nm}$ for samples grown on PET and glass substrates at room temperature are shown in Figures 10 and 11, respectively.

The optical transmission spectrum for sample PZO4 (Figure 10), which was the thinnest film according to X-ray diffraction patterns, shows the highest transmission, contrary to sample $\mathrm{PZO} 2$ which was the thickest film showing the lower transmission. From the transmission spectra the band gap energy was obtained from each sample. It was not possible to determine the band gap energy of the sample PZO5 through this method. In general, it can be observed that there is not so much variation in the value of the band gap energy, which remains constant independently of the conditions of the growth parameters. Sample PZO4, which presents the higher transmission of around $70 \%$, showed the best value of the band gap energy which is the closest to bulk $\mathrm{ZnO}$ of $3.37 \mathrm{eV}$.

The optical transmission spectra for samples GZO4 and GZO5 grown on glass substrate (Figure 11) show good transparency in the visible range, which were the thinnest films according to X-ray diffraction patterns. From the 


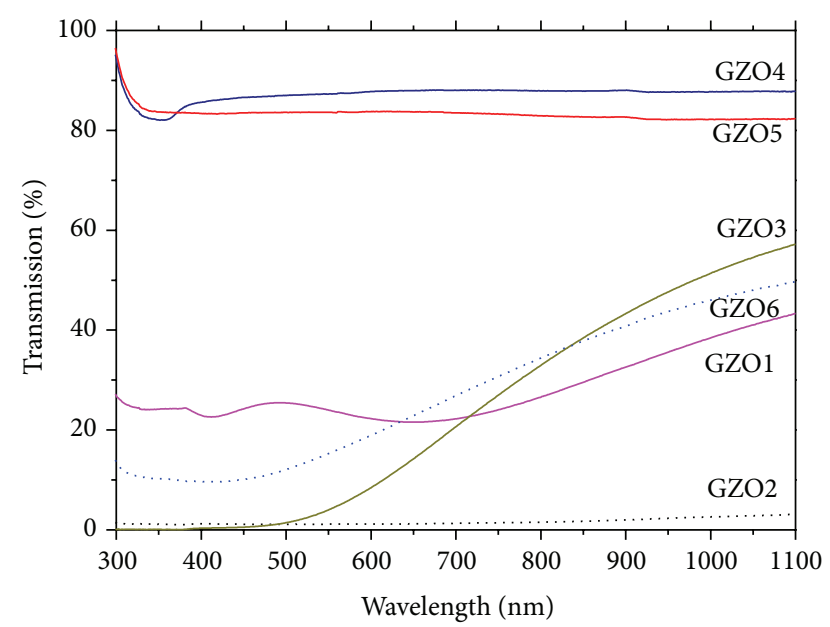

FIgURE 11: Optical transmission spectra of $\mathrm{ZnO}$ nanowires grown on glass substrate.

transmission spectra the energy gap $E_{g}$ was obtained from each sample (Table 1). It was not possible to determine the energy band gap of the sample GZO5 through this method. Sample GZO4 with band gap energy of $3.33 \mathrm{eV}$ and with a transmission of around $88 \%$ shows the closest value to bulk $\mathrm{ZnO}$ of $3.37 \mathrm{eV}$. XRD patterns show that when the heating time is $5 \mathrm{~min}$ there is a preferential growing of $\mathrm{ZnO}$ at $350 \mathrm{~W}$, which is observed by the reflection at $31.64^{\circ}$ corresponding to the direction (100), and for $700 \mathrm{~W}$ it is observed by the reflection at $34.27^{\circ}(002)$. On the other hand, when the heating time is $35 \mathrm{~min}$ there is not a preferential growth of $\mathrm{ZnO}$ that in both conditions of $350 \mathrm{~W}$ and $700 \mathrm{~W}$ is observed by the reflections at $31.64^{\circ}, 34.27^{\circ}$, and $36.16^{\circ}$ (101). These results are in agreement with that observed in the SEM images.

\section{Conclusions}

$\mathrm{ZnO}$ nanowires were grown on several substrates (PET, glass, and $\mathrm{Si}$ ) by the hydrothermal method using a rapid microwave heating process. It was possible to vary the diameters of the $\mathrm{ZnO}$ nanowires altering the power and heating time for achieving $\mathrm{ZnO}$ nanowires with diameters smaller than $50 \mathrm{~nm}$. Using the same growth parameters on the three substrates, it can be observed that in high power $(700 \mathrm{~W})$ and varying the heating time of 5 to 35 min the growth of $\mathrm{ZnO}$ nanowires on PET is favored, but heating conditions, as $700 \mathrm{~W}$ and $5 \mathrm{~min}$, promote the preferential orientation in c-axis directions in all the three substrates. On PET substrate at $700 \mathrm{~W}$ of furnace power, a correlation between the heating time and the diameter of nanowires was observed. For larger heating time, smaller diameter and larger length are obtained in the nanowires. For heating time of $5 \mathrm{~min}$, the nanowires grow aligned perpendicular to the substrate. At $700 \mathrm{~W}$ of furnace power, the growing of $\mathrm{ZnO}$ nanowires on PET, glass, and Si substrates showed a correlation between the heating time and the length of nanowires. For larger heating time, larger length is obtained. The value of the band gap energy obtained for the samples grown on PET and glass remains almost constant independently of the growth parameters.

\section{Conflict of Interests}

The authors declare that there is no conflict of interests regarding the publication of this paper.

\section{Acknowledgment}

This work was supported by SIP, Project 20144394, Mexico.

\section{References}

[1] Z. L. Wang, "Zinc oxide nanostructures: growth, properties and applications," Journal of Physics: Condensed Matter, vol. 16, no. 25, pp. R829-R858, 2004.

[2] G. Agarwal and R. F. Speyer, "Current change method of reducing gas sensing using $\mathrm{ZnO}$ varistors," Journal of the Electrochemical Society, vol. 145, no. 8, pp. 2920-2925, 1998.

[3] C. X. Wang, G. W. Yang, C. X. Gao et al., "Highly oriented growth of $\mathrm{n}$-type $\mathrm{ZnO}$ films on p-type single crystalline diamond films and fabrication of high-quality transparent $\mathrm{ZnO}$ /diamond heterojunction," Carbon, vol. 42, no. 2, pp. 317321, 2004.

[4] X. Y. Kong and Z. L. Wang, "Spontaneous polarizationinduced nanohelixes, nanosprings, and nanorings of piezoelectric nanobelts," Nano Letters, vol. 3, no. 12, pp. 1625-1631, 2003.

[5] C. Y. Lee, S. Y. Li, P. Lin, and T.-Y. Tseng, "Field-emission triode of low-temperature synthesized $\mathrm{ZnO}$ nanowires," IEEE Transactions on Nanotechnology, vol. 5, no. 3, pp. 216-219, 2006.

[6] R. Martins, E. Fortunato, P. Nunes et al., "Zinc oxide as an ozone sensor," Journal of Applied Physics, vol. 96, no. 3, pp. 1398-1408, 2004.

[7] W. I. Park, G. C. Yi, M. Kim, and S. J. Pennycook, "ZnO nanoneedles grown vertically on $\mathrm{Si}$ substrates by non-catalytic vapor-phase epitaxy," Advanced Materials, vol. 14, no. 24, pp. 1841-1843, 2002.

[8] L. E. Greene, M. Law, J. Goldberger et al., "Low-temperature wafer-scale production of $\mathrm{ZnO}$ nanowire arrays," Angewandte Chemie-International Edition, vol. 42, no. 26, pp. 3031-3034, 2003.

[9] L. Vayssieres, "Growth of arrayed nanorods and nanowires of $\mathrm{ZnO}$ from aqueous solutions," Advanced Materials, vol. 15, no. 5, pp. 464-466, 2003.

[10] M. Law, L. E. Greene, J. C. Johnson, R. Saykally, and P. Yang, "Nanowire dye-sensitized solar cells," Nature Materials, vol. 4, no. 6, pp. 455-459, 2005.

[11] H. E. Unalan, P. Hiralal, N. Rupesinghe, S. Dalal, W. I. Milne, and G. A. J. Amaratunga, "Rapid synthesis of aligned zinc oxide nanowires," Nanotechnology, vol. 19, no. 25, Article ID 255608, 2008.

[12] C. Mejía-García, E. Díaz-Valdés, G. Ortega-Cervantes, and E. Basurto-Cazares, "Synthesis of hydrothermally grown zinc oxide nanowires," Journal of Chemistry and Chemical Engineering, vol. 6, pp. 61-64, 2012. 

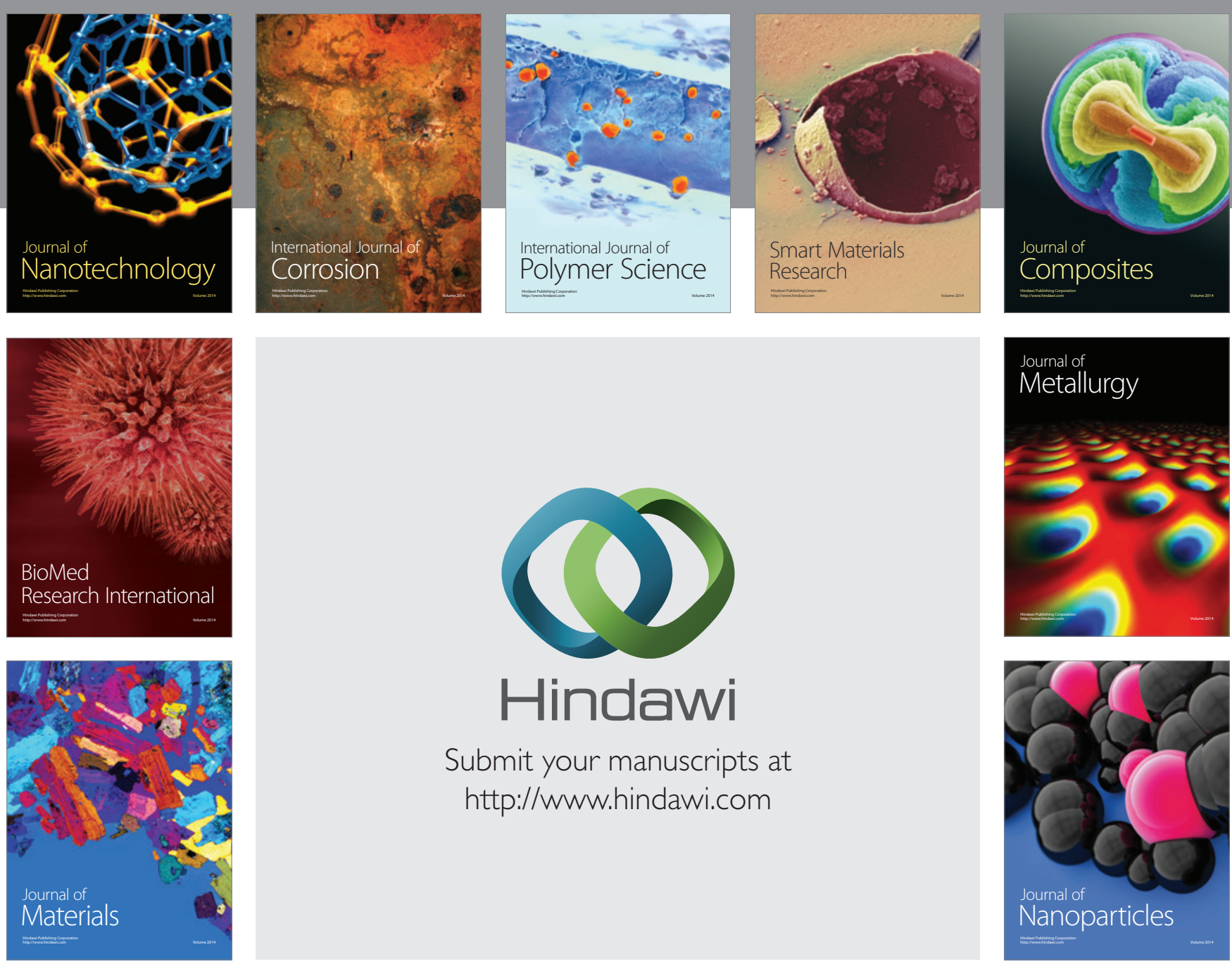

Submit your manuscripts at http://www.hindawi.com
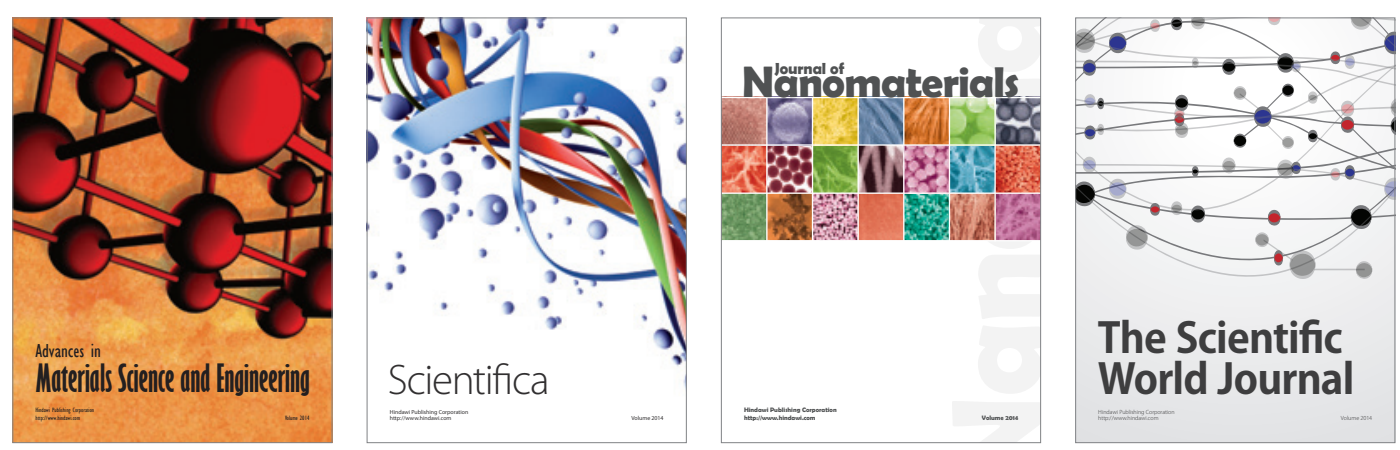

\section{The Scientific World Journal}
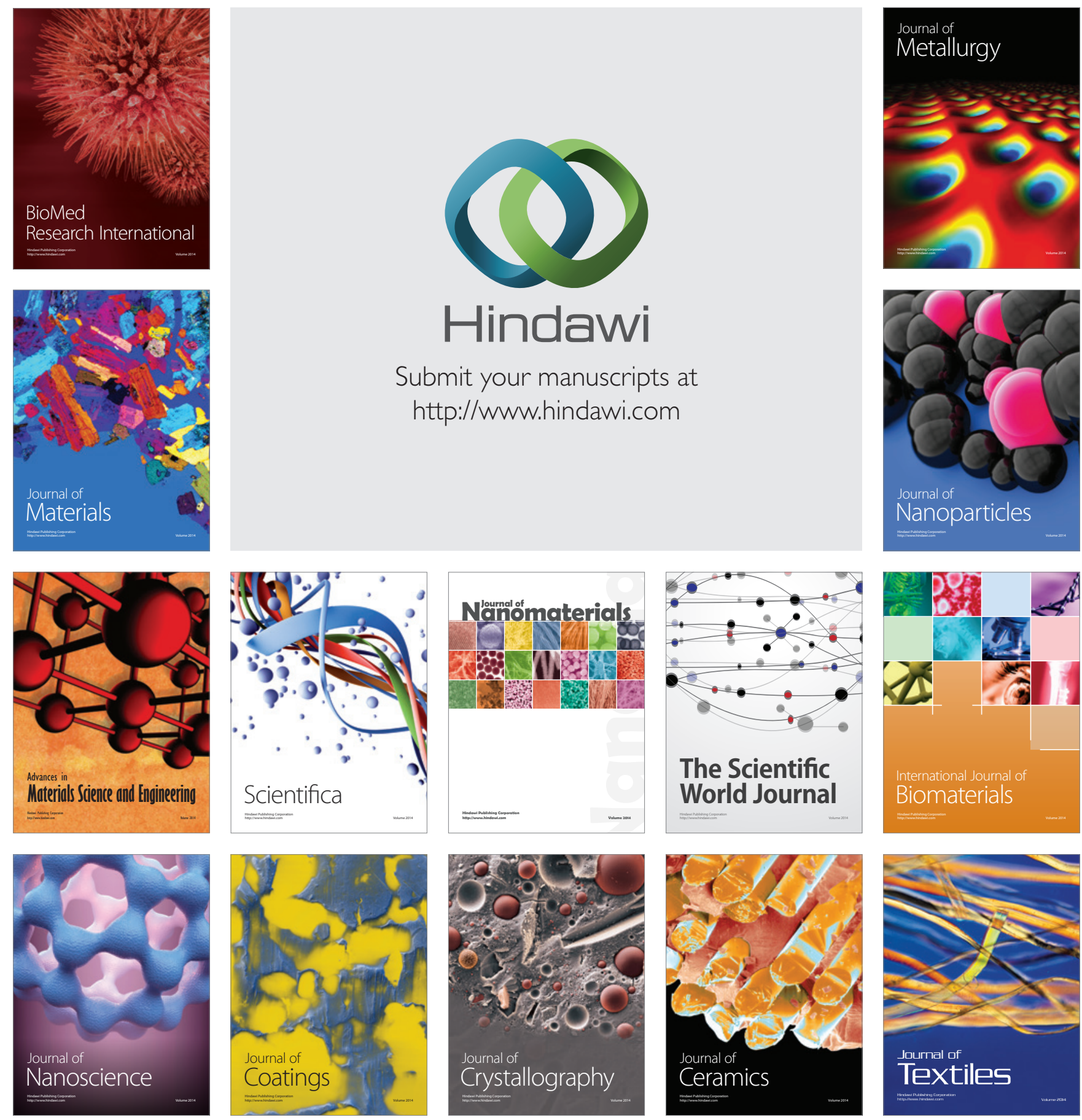